\title{
Online Monitoring of a Synchronous Generator's Capability with MATLAB
}

\author{
Prabesh Khadka Dietmar Winkler Thomas Øyvang \\ University of South-Eastern Norway, corresponding author: thomas . oyvang@usn. no
}

\begin{abstract}
The future power systems are expected to operate closer to its security and stability limits mainly due to growth in variable renewable generation and the increase in load demand. In particular, voltage stability has been a major subject of discussion and concern in electric power system operation and planning worldwide. This evolution of the power system demands enhancement in ability from large synchronous generators to respond to change in demand and supply. In this contribution, a new visualization tool for online monitoring of a synchronous generator's capability is presented. In addition, the proposed tool is illustrated with a long-term voltage stability simulation carried out on a 10-bus benchmark power system. It is shown that the load models, load tap changing transformer and generator over-excitation limiter have a significant influence on voltage stability and collapse phenomena.
\end{abstract}

Keywords: generator capability diagram, visualization tool, long-term voltage stability, PSAT, MATLAB

\section{Introduction}

Voltage stability is becoming one of the major concern in power system operation and planning worldwide due to the increased power demand. Many incidents of voltage collapse have been reported at different corners of the world and few examples can be found in CIGRE report (CIGRE Task Force 38.02.10 1993). The inability of the power system to meet the reactive power demand in an electrical network is one of the causes of voltage instability. Generators are normally the sources of reactive power support during voltage insecurities. Thus, monitoring the voltage profiles, voltage regulation and the reactive power output of generators is one of the important countermeasures for voltage collapse.

In a recent Ph.D. study (Øyvang 2018), utilization of the thermal capacity of a synchronous generator to enhance the voltage stability of the power system was studied. The available voltage control capability depends upon the temperature rise of the machine during contingencies (Øyvang 2018). Furthermore, the normal limits of operation of generators without exceeding their thermal limitations are defined by the reactive capability curve. The method of determining the capability curves are described by various authors in different papers as in (Pejovski, Velkovski, and Najdenkoski 2016) and (I.Ili et al. 2007). However, the de- velopment of an automatic visualization tool which monitors the generator's operating conditions in real-time with sophisticated visualization adds quality to the usefulness of the PQ diagram.

This paper will primarily address the implementation of PQ capability diagram for online monitoring of the generator's capability in MATLAB through a visualization tool. In addition, long term voltage stability or the collapse phenomenon which includes the dynamics of slow acting components such as transformer under-load tap changer (ULTC), generator overexcitation limiter (OXL) and thermostat controlled loads, has been investigated in this research work along with the visualization of its result in the visualization tool. The dynamic simulation is carried out on Kundur 10-bus test system (Kundur 1994), in MATLAB based power system toolbox PSAT; a Free and Open Source Software (FOSS) which includes different static and dynamic power system component models. Moreover, the PQ capability diagram is implemented in the MATLAB programming language with the help of Graphical User Interface.

This paper is organized as follows. Section 2 gives a brief introduction to the generator PQ capability diagram. Section 3 presents the model formulation and the development of a automatic visualization tool. In Section 4, the dynamic voltage stability analysis of a test power system is demonstrated whereas the temperature visualization of a hydrogenerator in the visualization tool is shown in Section 5. The simulation results and the discussions are included in Section 6.

\section{Generator capability curve}

Synchronous generator is a primary source of reactive power in the network and plays an important role in maintaining the voltage stability in the network. The boundaries for supplying the reactive power at a given active power output is defined by the generator capability curve provided by the manufacturers (Dragosavac et al. 2012). Following operational constraints are the reasons for the limits in active and reactive power of the synchronous generator (Machowski, Bialek, and Bumby 2008).

1. Armature current limit.

2. Field current limit.

3. Steady-state stability limit. 
4. Stator end region heating limit.

5. Generator active power limit.

Figure 1 shows the synchronous generator capability diagram where the area bounded by the curve $A B C D E F G$ indicates the safe region of operation for salient-pole machine.

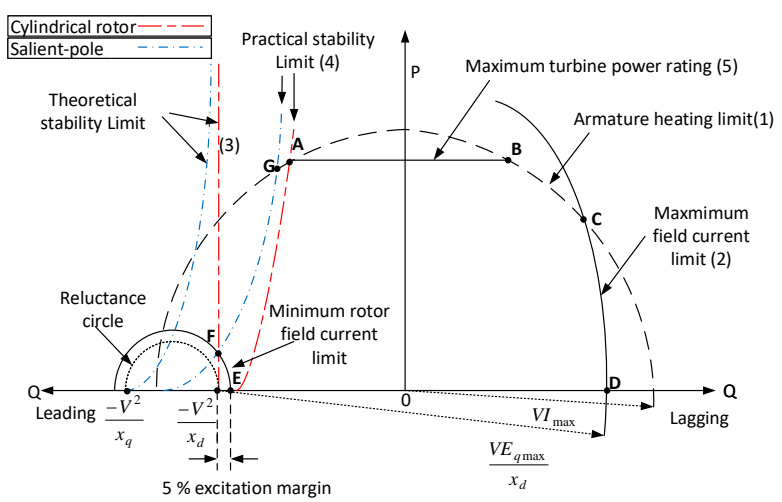

Figure 1. Capability diagram of synchronous generator (Walker 1953).

\section{Model development}

This paper presents the methodology for obtaining the PQ diagram for a cylindrical rotor synchronous generator with the following simplification during its modelling:

- The synchronous generator has been assumed to be connected to the infinite bus, i.e., with constant voltage.

- The machine saturation effect on the direct axis synchronous reactance has not been considered, i.e., $x_{d}=$ constant

- The effect of armature resistance has also been neglected.

The rated parameters of generator G3 in local area in the Kundur 10-bus system (Kundur 1994) is taken as reference for determining capability diagram with $10 \%$ stability margin.

The theoretical PQ diagram can be derived by dividing every phasor in the vector diagram by direct-axis synchronous reactance $x_{d}$ and multiplying them with the armature voltage as shown in Figure 2. The figure so obtained, contains $P$ and $Q$ as the $\mathrm{x}$-axis and y-axis respectively.

\subsection{Rated turbine power limit}

The maximum and the minimum turbine power limits are drawn according to the following two conditions (I.Ili et al. 2007):
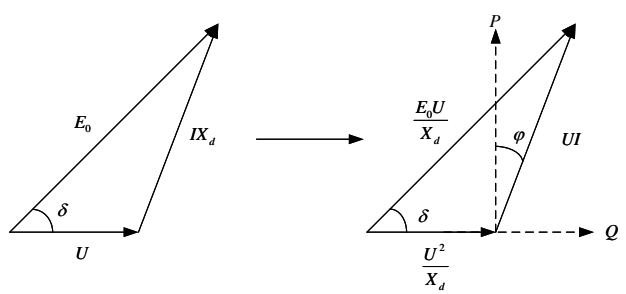

Figure 2. Derivation of a P-Q capability diagram from the phasor diagram (cylindrical rotor) (Vrazic, Viskovic, and Hanic 2014).

- If the power of the turbine $\left(P_{T}\right)$ exceeds the rated power of the generator $\left(P_{n}\right)$, i.e., if $P_{T}>P_{n}$, then $P_{\max }=P_{n}$.

- If the power of the turbine is equal to or less than the rated power of the generator $\left(P_{T} \leq P_{n}\right)$, then $P_{\max }=$ $P_{T} \cdot \eta_{G}$

This limit is indicated in Figure 3 as $P_{\max }$. The minimum power depends upon the turbine requirements regarding turbine efficiency. For example, in Kaplan and Francis turbine minimum power output is $5 \%$ to $30 \%$ of rated output whereas in some turbines like Pelton turbine this limitation does not exists (I.Ili et al. 2007).

\subsection{Rated stator current limit}

The rated stator current limit is plotted as a constant semicircle with center at origin ' 0 ' and radius as the rated apparent power, $S_{n}$ as shown in Figure 3. Point 'P' denotes the rated operating condition of the generator. The typical operating point is considered as $\cos \phi_{n}=0.72$. So,

$$
\begin{aligned}
P_{\text {rated }} & =S_{n} \cos \phi=1 \cdot 0.72=0.72 \text { p.u. } \\
Q_{\text {rated }} & =S_{n} \sin \phi=1 \sqrt{1-(\cos \phi)^{2}}=0.69 \text { p.u. }
\end{aligned}
$$

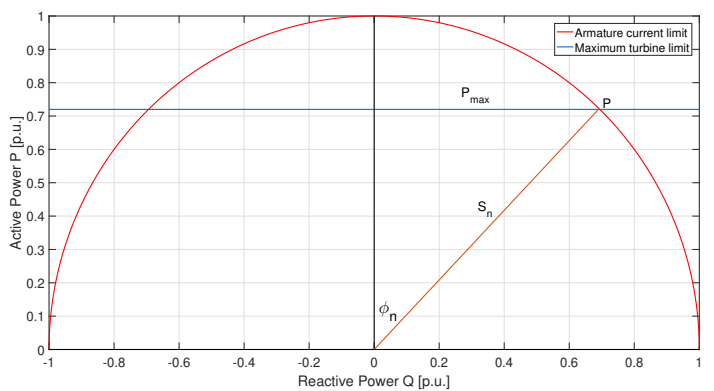

Figure 3. Rated stator current limit and maximum turbine limit plot.

\subsection{Rated field current limit}

For implementing the rated field current limit, an arc is drawn with the center at $\left(0,-\frac{V^{2}}{x_{d}}\right)$ and radius $\frac{E_{q_{\max }} V}{x_{d}}$ from 
$\cos \phi=0$ to $\cos \phi=0.72$ (rated) where $E_{q_{\max }}$ is calculated from the phasor diagram as shown in Figure 2 as:

$$
E_{q_{\max }}=\sqrt{\left(V+I x_{d} \sin \phi\right)^{2}+\left(I x_{d} \cos \phi\right)^{2}}
$$

The limit is drawn as curve PK in Figure 4.

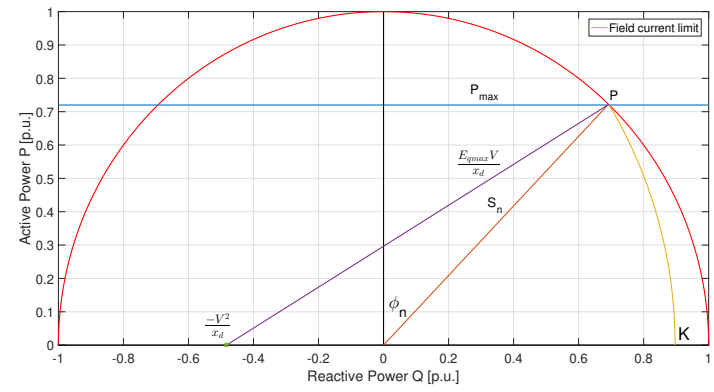

Figure 4. Rated field current limit plot.

\subsection{Practical Stability limit}

For round-rotor generators, theoretical stability limit is achieved at load angle $\delta=90^{\circ}$. However, the theoretical stability curve is reduced by a constant power value, for example by $10 \%$ of the rating of the machine as a safety margin and the corresponding curve so obtained is termed as practical stability margin (Walker 1953).

The theoretical stability curve is drawn as a straight line at point $\left(0,-\frac{V^{2}}{x_{d}}\right)=\left(0,-\frac{1}{2.07}\right)=(0,-0.48)$ represented by dashed line in Figure 5. The practical stability limit is represented as curve $\mathrm{AD}$ in the same figure.

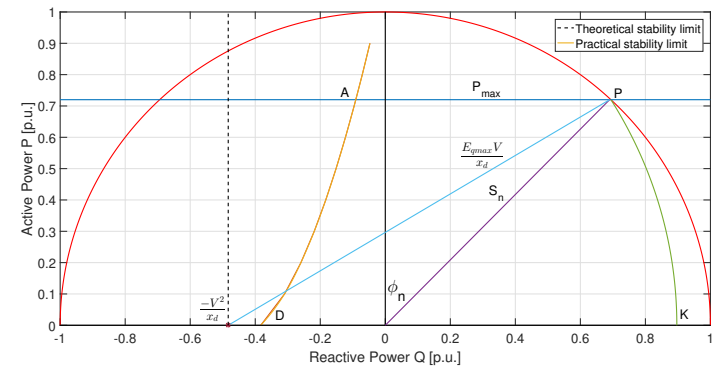

Figure 5. Theoretical and practical stability limit plot.

Hence, the safe region for the operation of a synchronous generator is represented by the area bounded by curve APKD in Figure 5.

\subsection{Visualization tool}

As discussed earlier in this section, various operational limits in PQ diagram was implemented in the MATLAB software environment. For improved visualization of the diagram, a visual App was created using MATLAB App designer. The App yields a more accurate approximation to test for conditions of instability as it provides enhanced online information of the system. A Graphical User Interface was created by using different components from the component library and specifying app's design and layout. For defining the App behavior, App designer allows an integrated version of the MATLAB Editor (MATLAB App Designer 2019). All the parameter values implemented, and the dynamics observed in the visualization tool is based upon the case study of Kundur 10-bus test system which is described further in Section 4.

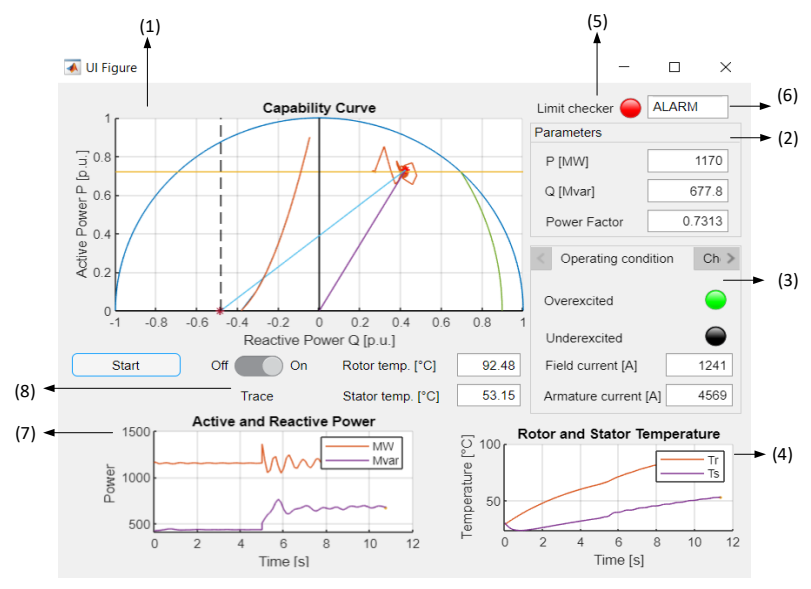

Figure 6. Graphical User Interface for generator capability diagram.

Figure 6 shows a GUI environment for the designed App in order to visualize the generator capability. The GUI consists of three figure windows and two main tabs. The upper figure (1) in the user interface shows the capability curve with the real-time operating point as indicated by 'red' asterisk symbol. The 'Parameters' tab (2) shows the operating point $(\mathrm{P}$ and $\mathrm{Q})$ values in real time along with the operational power factor. The 'Operating conditions' tab (3) shows the actual operating condition, i.e., whether the generator is operating in over excitation mode or under excitation mode with current operation mode indicated by lamp glowing 'green'. The 'Machine Paramters' tab as shown in Figure 7 indicates the generator rated conditions which can be changed by changing the values in the respective fields. For example, the effect of change of direct axis synchronous reactance on the generator limits can be visualized in the figure section (1) by changing its value in the 'Machine rating' tab. The two lower figure windows (7) and (4) shows the plot of active and reactive power, and the plot of rotor and stator temperature of the synchronous machine respectively.

On top of the 'Parameters' tab resides a 'Limit checker' (5) as indicated by a lamp which glows 'red' when the defined operational limits on the capability curve are violated along with the actuation and information of 'ALARM' (6) to notify the operating personnel about the limit violation as shown in Figure 6. The lamp glows 'green' along with an information 'NORMAL' when the operating point lies within the defined boundaries as shown in Figure 7. The 'Trace' button (8) is used to turn on or turn off the trace of the operating point's path which 
is as shown in Figure 6 and Figure 7 respectively.

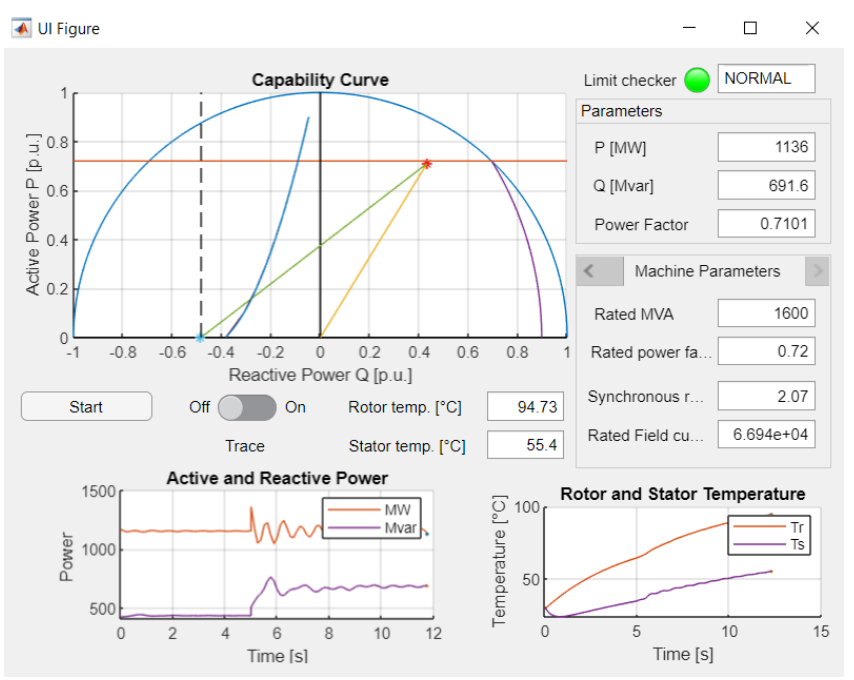

Figure 7. Graphical User Interface for Generator Capability Diagram showing 'NORMAL' condition.

\section{Case study}

As a case study, the long term voltage stability analysis is carried out on a 10-bus benchmark power system, and the dynamics involved during the simulation is visualized in the automatic visualization tool.

\subsection{Description of a test system}

The Kundur-10 bus test system (Kundur 1994) is chosen in order to analyze the performance and influence of different power system components in voltage stability. The test system used for the study is actually based on the system described in (CIGRE Task Force 38.02.08 1995) as BPA ${ }^{1}$ test system, with some changes in load and compensating devices parameters. The necessary data used for the simulation of the system is provided in Appendix A.

Here the generators G1 and G2 in remote areas supply loads to the local area through five $500 \mathrm{kV}$ transmission lines. The local generator $\mathrm{G} 3$ at bus 3 generates $1154 \mathrm{MW}$ and the remaining power is supplied by two remote generators. Shunt capacitors are placed at various locations in the local area. Figure 8 shows the implementation of test system in PSAT.

\subsection{Simulation results}

The voltage at bus 11 and the reactive power output of the generator G3 is compared for the test system including and excluding the overexcitation limiter (OXL) with under-load tap changer (ULTC) in action for both cases, which are as presented in the Figure 9 and Figure 10 respectively.

The sequence of events triggered during the simulation in different time frames can be explained as follows.

\footnotetext{
${ }^{1}$ Bonneville Power Administration https : / / www . bpa . gov
}

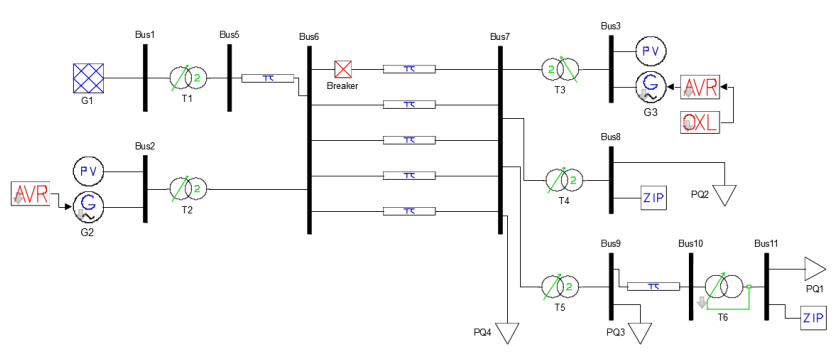

Figure 8. Single line diagram implementation of the test system in PSAT.

- One of the transmission lines is disconnected at time $\mathrm{t}=5$ seconds. When the line has been disconnected, the apparent impedance and consequently the line losses and voltage drop of the transmission system is increased.

- The second time frame starts at around 10 seconds where the ULTC is activated as the voltage at the bus 11 is lower than the preset value. The ULTC tries to keep the voltage at the secondary bus (bus-11) at its original value by adjusting its tap ratio which demands more reactive power support from the generators present in the network. Thus, to meet the increased reactive power demand the excitation current is continuously increased until the maximum tap of transformer is reached or voltages at the buses are recovered. This time frame can be observed in Figure 9a and Figure 10a. The voltage at bus 11 is restored to nearly its reference value in about $90 \mathrm{sec}-$ onds as shown in Figure 9.

- The third time frame begins with the actuation of overexcitation limiter as shown in Figure $9 \mathrm{~b}$ at around $\mathrm{t}=150$ seconds by ramping down the field current. The following chains of events occurs after the actuation of OXL.

- As the field current of G3 is reduced, its terminal voltage drops.

- Voltages at bus 11, 10 and 7 drops.

- ULTC on T6 tries to restore the voltage at bus 11 back to its original value.

- The reactive power demand on generators increases. Field current of machine 3 increases and continues to remain at its limit and the terminal voltage of G3 further decreases.

- Voltage at bus 7 drops and causes a further reduction in terminal voltage of bus 10 and bus 11.

- The ULTC operates again, repeating above mentioned chains of events.

Hence in response to each tap movement of ULTC, the voltage at bus 11 reduces rather than increased. 


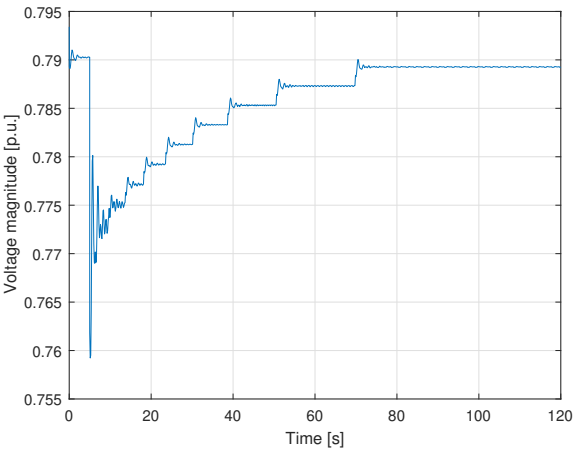

(a) With only ULTC

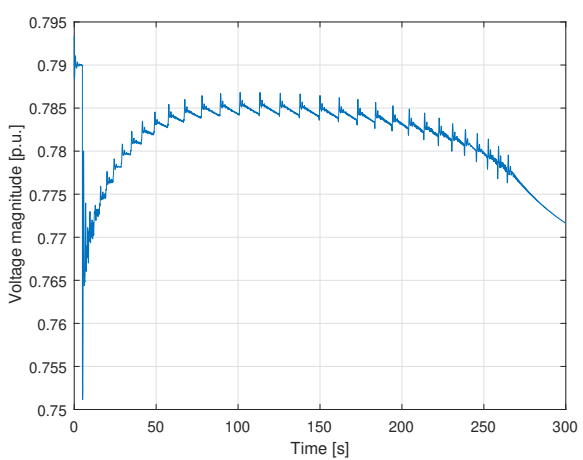

(b) With ULTC and OXL

Figure 9. Bus 11 voltage without and with OXL.

This indicates that the system has entered into the voltage instability phase. The bus 11 voltage falls progressively as shown in Figure 9b until the ULTC reaches its maximum tap position at around 260 seconds. The voltage at bus 11 settles at around 0.77162 p.u.

Furthermore, the effect of static load models on long term voltage stability was studied for the test case considered. Figure 11 shows the voltage profile at bus 11 when the load at bus 8 is modelled as constant impedeance, constant current and constant power load keeping the load at bus 11 as constant impedeance. The ULTC and OXL were kept inactive during this condition and transformer T6 is implemented as a fixed tap transformer with tap ratio same as that of transformer T5.

It is observed that the constant power load stabilizes at a lower value as compared to constant impedance and constant power load because of its load restoring characteristics (Nguyen 2008). That means constant power load tries to consume the same power at a pre-disturbance level as consumed power is independent of voltage variations and hence the voltage drops even further. The dynamics of voltage profile obtained is comparable to the similar case study performed in Ph.D. thesis (Nguyen 2008) using PSS/E software.

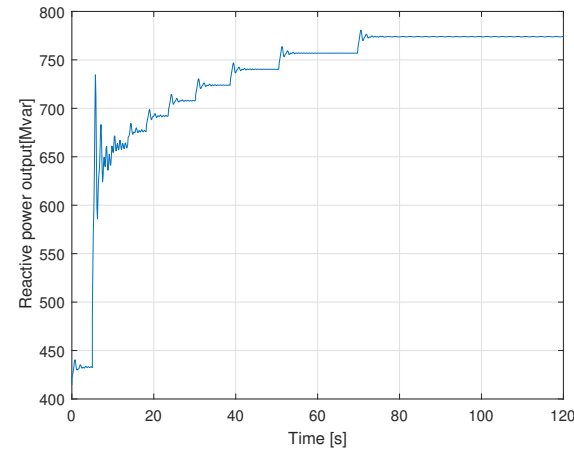

(a) With only ULTC

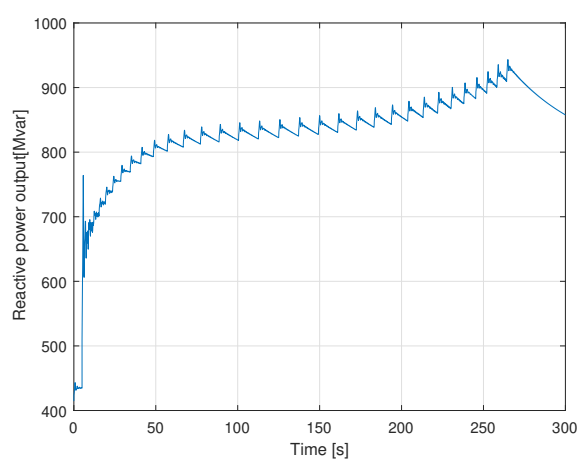

(b) With ULTC and OXL

Figure 10. Reactive power output of generator G3 without and with OXL.

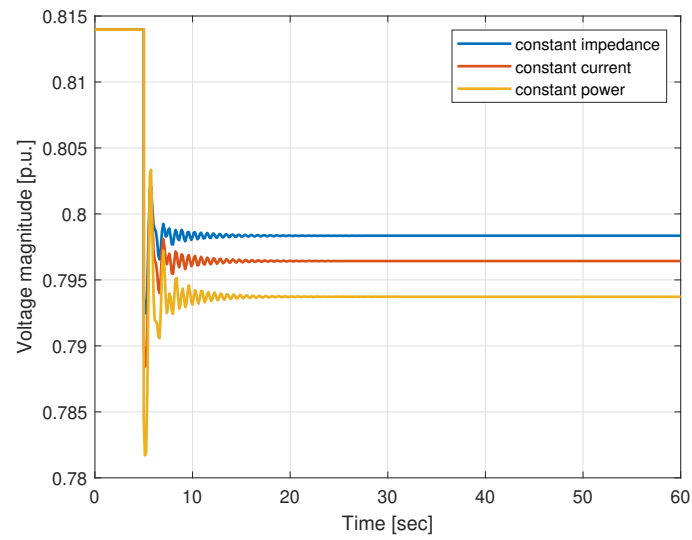

Figure 11. Voltage profile at bus 11 for different load types.

\section{Temperature visualization}

The temperature development in the stator and rotor windings of the synchronous generator was also observed in the same tool by using the thermal model as described in (Øyvang 2018). This is shown in Figure 13. Figure 12 shows the thermal model implemented in Simulink software environment. The output temperatures as seen in the figure is the result of input field current and armature current taken from the local generator G3 in Kundur 10-bus system when replaced by 103 MVA hydrogenerator at 'Åb- 
jøra' in Norway. The machine data of hydrogenerator is provided in Table 6 . The field and the stator currents in real time are observable in the tool. The initial temperature in the stator and rotor was taken as $28^{\circ} \mathrm{C}$ during the simulation.

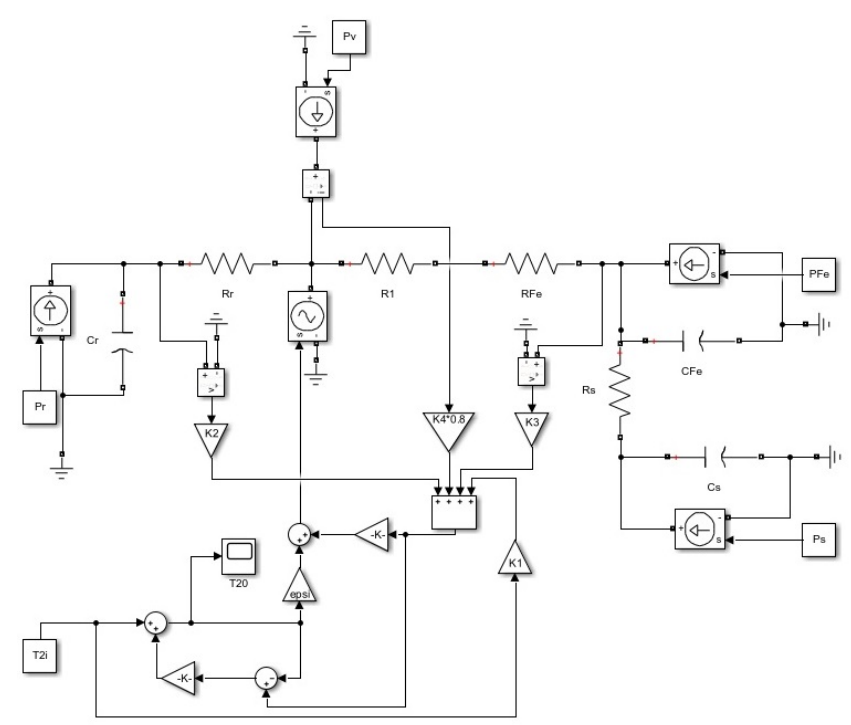

Figure 12. Simulink circuit for the thermal model proposed in (Øyvang 2018)

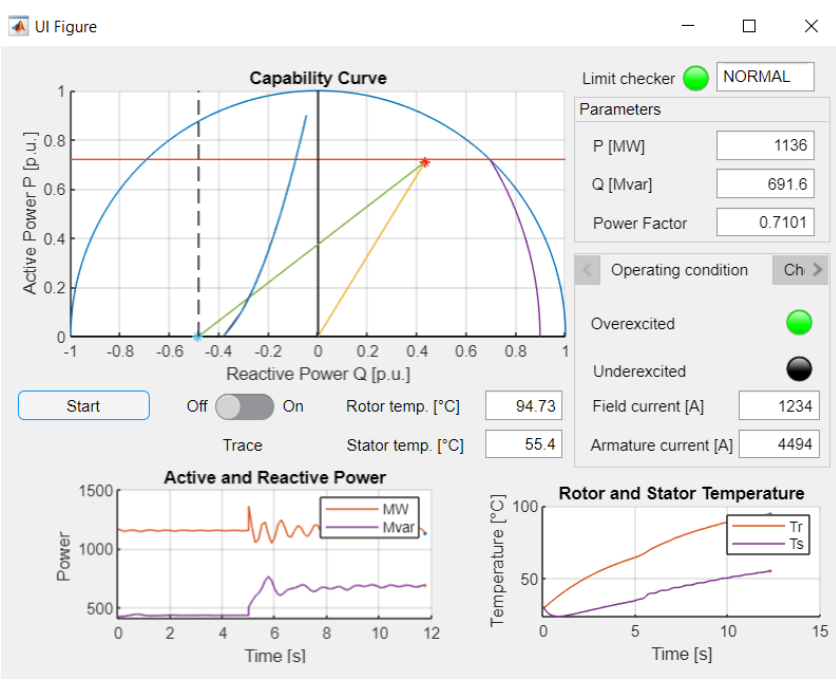

Figure 13. Temperature observation in the visualization tool.

\section{Conclusion and further work}

This paper proposes a visualization tool for the online monitoring and visualization of a generator's capability. The tool was developed using a MATLAB software environment with the help of Graphical User Interface which provides the user interaction with the visualization tool through graphical displays, inputs, and visual indicators. The tool provides power factor, active and reactive power in real-time along with an alarm signal in the case of limit violation. For the validation of the tool, a simulation regarding a long term voltage stability analysis is carried out and the dynamics involved are shown in the same tool.

Furthermore, the effect of ULTC, overexcitation limiter and the static loads on the voltage collapse scenario is presented in this paper. The severity of effect depends upon the type of load.

Future work will focus on the implementation of additional characteristics in the tool such as stator end region heating limit, the temperature dependence of the generator limits and the variable terminal voltage. In addition, the effect of dynamic load characteristics which has a significant influence on voltage stability can be analyzed further.

\section{References}

CIGRE Task Force 38.02.08. Long Term Dynamics Phase II. Tech. rep. CIGRE, 1995.

CIGRE Task Force 38.02.10 . Modelling of Voltage Collapse Including Dynamic Phenomena. Tech. rep., 1993.

J. Dragosavac et al. On-line Estimation of Available Generator Reactive Power for Network Voltage Support. In 8th Mediterranean Conference on Power Generation, Transmission, Distribution and Energy Conversion (MEDPOWER 2012). Institution of Engineering and Technology. DOI: 10.1049/ CP. 2012. 2014, 2012

I. Ili et al. Methodology for Determining the Actual PQ Diagram of a Hydrogenerator. In Journal of Energy 56.2, pp. 144-181. URL: https:// hrcak. srce.hr/13153, 2007

Prabha Kundur. Power System Stability and Control. McGraw-Hill, Inc., 1994.

Jan Machowski, Janusz W. Bialek, and James R. Bumby. Power System Dynamics : Stability and Control. 2nd ed., John Wiley \& Sons Ltd, 2008.

MATLAB App Designer. URL: https : / / se . mathworks . com / products / matlab / app designer.html (visited on 03/22/2019), 2019.

Dang Toan Nguyen. Contributions to analysis and prevention of power system blackouts. Theses. Institut National Polytechnique de Grenoble - INPG. URL: https://tel.archives-ouvertes.fr/ tel-00352414, Nov. 2008.

Thomas Øyvang. Enhanced power capability of generator units for increased operational security. PhD thesis, 2018.

Dejan Pejovski, Bodan Velkovski, and Krste Najdenkoski. MATLAB Model for Visualization of PQ diagram of a Synchronous Generator. URL: https : / / www . researchgate . net / publication 312190893 _MATLAB_Model_for_Visualization_of_PQ_diagram_of_a_Synchronous_Generator, 2016. 
M. Vrazic, A. Viskovic, and Z. Hanic. User P-Q

Diagram as a Part of a Synchronous Generator

Monitoring System. Electronics and Electrical

Engineering, 20(4). DOI: $10.5755 /$

j01.eee.20.4. 5333.

J. H. Walker. Operating characteristics of salient-pole machines. In: Proceedings of the IEE -Part II: Power Engineering 100.73, pages 13-24. DOI: $10.1049 / \mathrm{pi}-2.1953 .0004$, Feb. 1953. 


\section{A Data for Test System}

$$
S_{\text {base }}=100 \mathrm{MVA}
$$

Table 1. Bus Data

\begin{tabular}{lcccccc}
\hline $\begin{array}{l}\text { Bus } \\
\text { No }\end{array}$ & $\begin{array}{c}\text { Base } \\
{[\mathrm{kV}]}\end{array}$ & $\begin{array}{c}V_{\text {scheduled }} \\
{[\mathrm{p} . u .]}\end{array}$ & $\begin{array}{c}\text { Phase } \\
{[\mathrm{rad}]}\end{array}$ & $\begin{array}{c}Q_{\text {shunt }} \\
{[\text { Mvar] }}\end{array}$ & $\begin{array}{c}P_{\text {load }} \\
{[M W]}\end{array}$ & $\begin{array}{c}Q_{\text {load }} \\
\text { [Mvar] }\end{array}$ \\
\hline 1 & 13.8 & 0.98 & 0 & 0 & 0 & 0 \\
2 & 13.8 & 0.96 & 0 & 0 & 0 & 0 \\
3 & 13.8 & 1.04 & 0 & 0 & 0 & 0 \\
5 & 500 & 1.00 & 0 & 0 & 0 & 0 \\
6 & 500 & 1.00 & 0 & 0 & 0 & 0 \\
7 & 500 & 1.00 & 0 & 750 & 0 & 0 \\
8 & 13.8 & 0.94 & 0 & 1500 & 3000 & 1800 \\
9 & 115 & 0.95 & 0 & 300 & 0 & 0 \\
10 & 115 & 0.89 & 0 & 0 & 30 & 0 \\
11 & 13.8 & 0.91 & 0 & 0 & 3100 & 90 \\
\hline
\end{tabular}

Table 2. Generators load flow data

\begin{tabular}{cccccccc}
\hline $\begin{array}{c}\text { Bus } \\
\text { No }\end{array}$ & Name & Base & $P_{\text {gen }}$ & $Q_{\text {gen }}$ & $S_{\text {base }}$ & $Q_{\max }$ & $Q_{\min }$ \\
& {$[M W]$} & {$[M v a r]$} & {$[M V A]$} & {$[M v a r]$} & {$[M v a r]$} \\
\hline 1 & G1 & 13.8 & 3471.9 & 1129.03 & 5000 & 1600 & -1000 \\
2 & G2 & 13.8 & 1736 & 712.53 & 2200 & 725 & 200 \\
3 & G3 & 13.8 & 1154 & 414.58 & 1600 & 700 & -100 \\
\hline
\end{tabular}

Table 3. Transmission lines data

\begin{tabular}{|c|c|c|c|c|}
\hline $\begin{array}{c}\text { From } \\
\text { Bus }\end{array}$ & $\begin{array}{c}\text { To } \\
\text { Bus }\end{array}$ & $\begin{array}{c}R \\
{[p . u .]}\end{array}$ & $\begin{array}{c}X \\
\text { [p.u.] }\end{array}$ & $\begin{array}{c}B \\
\text { [p.u.] }\end{array}$ \\
\hline 5 & 6 & 0.0000 & 0.0040 & 0.0000 \\
\hline 6 & 7 & 0.0015 & 0.0288 & 1.1730 \\
\hline 9 & 10 & 0.0010 & 0.0030 & 0.0000 \\
\hline
\end{tabular}

Table 4. Transformers data

\begin{tabular}{cccc}
\hline Transformer & $\begin{array}{c}R \\
{[p . u .]}\end{array}$ & $\begin{array}{c}X \\
{[p . u .]}\end{array}$ & Tap ratio \\
\hline T1 & 0.0000 & 0.0020 & 0.8857 \\
T2 & 0.0000 & 0.0045 & 0.8857 \\
T3 & 0.0000 & 0.0125 & 0.9024 \\
T4 & 0.0000 & 0.0030 & 1.0664 \\
T5 & 0.0000 & 0.0026 & 1.0800 \\
T6 & 0.0000 & 0.0010 & 0.9750 \\
\hline
\end{tabular}

\section{Machine parameters:}

Machine 1: Infinite bus

Machine 2: $\mathrm{H}=2.09$, MVA rating $=2200 \mathrm{MVA}$

Machine 3: $\mathrm{H}=2.33$, MVA rating $=1400 \mathrm{MVA}$

Following are the parameters for machine 2 and ma-
Table 5. Thermal model data

\begin{tabular}{lccc}
\hline Parameters & Symbol & Value & Unit \\
\hline Thermal resistance, $T_{\mathrm{Fe}}-T_{\delta}$ & $R_{F e}$ & 0.07 & $\mathrm{~K} / \mathrm{kW}$ \\
Thermal resistance, $T_{s}-T_{F e}$ & $R_{S}$ & 0.05 & $\mathrm{~K} / \mathrm{kW}$ \\
Thermal resistance, air & $R_{1}$ & 0.018 & $\mathrm{~K} / \mathrm{kW}$ \\
Gain coefficient, $T_{2, i}$ & $\mathrm{~K} 1$ & 0.59 & - \\
Gain coefficient rotor(Cu) & $\mathrm{K} 2$ & 0.5 & - \\
Gain coefficient stator(Fe) & $\mathrm{K} 3$ & 0.36 & - \\
Heat exchanger effieicency (epsi) & $\varepsilon$ & 0.595 & - \\
\hline
\end{tabular}

Table 6. Machine data of Åbjøra (Øyvang 2018)

\begin{tabular}{lccc}
\hline Description & Parameters & Value & Unit \\
\hline Rated power & $S_{n}$ & 103 & $\mathrm{MVA}$ \\
Rated voltage & $V_{t n}$ & 11 & $\mathrm{kV}$ \\
Rated current & $I_{t n}$ & 5406 & $\mathrm{~A}$ \\
Rated field current & $I_{f d n}$ & 1064 & $\mathrm{~A}$ \\
Inertia constant & $H$ & 2.66 & $\mathrm{~s}$ \\
Number of polepairs & $p$ & 6 & - \\
Synchronous reactance d-axis & $x_{d}$ & 1.09 & [p.u.] \\
Synchronous reactance q-axis & $x_{q}$ & 0.67 & [p.u.] \\
Transient reactance d-axis & $x_{d}^{\prime}$ & 0.24 & [p.u.] \\
Subtransient reactance d-axis & $x_{d}^{\prime \prime}$ & 0.15 & [p.u.] \\
Subtransient reactance q-axis & $x_{q}^{\prime \prime}$ & 0.19 & [p.u.] \\
Transient OC Time constant d-axis & $T_{d o}^{\prime}$ & 10 & $\mathrm{~s}$ \\
Transient OC Time constant q-axis & $T_{q o}^{\prime}$ & 0.23 & $\mathrm{~s}$ \\
Subtransient OC Time constant d-axis & $T_{d o}^{\prime \prime}$ & 0.086 & $\mathrm{~s}$ \\
Subransient OC Time constant q-axis & $T_{q o}^{\prime \prime}$ & 0.23 & $\mathrm{~s}$ \\
Stator leakage inductance & $X_{l}$ & 0.08 & [p.u.] \\
Stator resistance & $R_{a}$ & 0.00182 & [p.u.] \\
\hline
\end{tabular}

chine 3 on their respective MVA ratings:

$$
\begin{aligned}
& R_{a}=0.0046 \quad X_{d}=2.07 \quad X_{q}=1.99 \\
& X_{l}=0.155 \quad X_{d}^{\prime}=0.28 \quad X_{q}^{\prime}=0.49 \\
& X_{d}^{\prime \prime}=0.215 \quad X_{q}^{\prime \prime}=0.215 \\
& T_{d o}^{\prime}=4.10 \quad T_{q o}^{\prime}=0.56 \\
& T_{d o}^{\prime \prime}=0.033 \quad T_{q o}^{\prime \prime}=0.062
\end{aligned}
$$

Exciters:

Both machine 2 and machine 3 uses thyristor exciters with a gain of 100 and the time delay of the measurement system as 0.02 seconds.

\section{Overexcitation limiter for machine 3:}

The OXL model used in the simulation is as described in Section 4.2 with integrator time constant $\left(T_{0}\right)=60$ seconds, maximum field current $i_{f d}^{l i m}=11.7$ p.u. and maximum output signal $v_{O X L}^{\max }=5.02$ p.u.

ULTC data for transformer T6 between bus 10 and bus 11:

Deadband: $\pm 1 \%$ p.u. bus voltage

Tap range: \pm 16 steps

Step size: $5 / 8 \%$ (=0.00625 p.u.) 